\title{
GRAFTING TEMBAGA(II) PADA SILIKA MODIFIKASI
}

\author{
Syukria $^{\mathrm{a}, \mathrm{b}}$, Hosli Hidayat ${ }^{\mathrm{a}, \mathrm{c}}$, Admi $^{\mathrm{a}}$ and Imelda ${ }^{\mathrm{a}}$ \\ ${ }^{a}$ Laboratorium Kimia Material Jurusan Kimia FMIPA Unand \\ bsyukri.darajat@yahoo.com
}

\begin{abstract}
A copper(II) acetonitrile complex has been grafted on modified silica and characterized by Fouruer Transform Infra Red (FTIR) and Energy Dispersive X-ray (EDX). The succesful experiment was confirmed by the appearance of shifted $\mathrm{CN}$ stretching vibration of acetonitrile on modified silica surface (FTIR analysis). The amount of copper(II) loaded by the silica was of $\sim 7 \%$ proven by EDX measurement.
\end{abstract}

Key words: Grafting process, modified silica, metal loading

\section{PENDAHULUAN}

Katalis memainkan peranan penting dalam berbagai proses industri seperti industri energi, bahan bakar, farmasi dan bahan kimia. Senyawa katalis juga telah menjadi salah satu unsur terpenting dalam proses sintesis, baik organik maupun anorganik dan merupakan topik yang selalu memancing minat para peneliti. Sifat dan bahan katalis juga dapat dimodifikasi, sehingga kegunaanya dapat ditingkatkan dan efek samping yang ditimbulkan ke lingkungan dapat ditekan seminimal mungkin. ${ }^{[1]}$

Senyawa komplek logam transisi telah banyak dipelajari sebagai katalis dalam beberapa reaksi organik. Sifat-sifat kimia yang dimiliki logam pusat akan memberikan pengaruh pada reaktifitas senyawa kompleks tersebut. ${ }^{[1-3]}$ Beberapa senyawa komplek dari tembaga(II) dengan asetonitril sebagai ligan pelarut (solvent ligand) telah berhasil disintesis baik pada fasa homogen maupun fasa heterogen. Pada fasa homogen, katalis senyawa komplek tembaga(II) ini memberikan hasil yang signifikan pada beberapa reaksi organik seperti aziridinasi dan siklopropanasi beberapa senyawa olefin. ${ }^{[4-7]}$

Masalah utama yang dimiliki katalis homogen pada umumnya adalah sulit untuk memisahkan katalis dengan produk yang terbentuk, sehingga tidak dapat dipakai ulang. Selain itu, akumulasi logam transisi dan ligan organik yang bersifat toksik dapat mencemari lingkungan sekitar. Usaha alternatif yang terus dikembangkan terkait nilai ekonomi dan isu lingkungan dari katalis homogen ini adalah dengan melakukan grafting (ditempelkan secara kimia) pada suatu material support, sehingga dihasilkan katalis yang heterogen. ${ }^{[8]}$

Senyawa komplek tembaga(II) dilaporkan telah berhasil diamoblisasi pada beberapa material support baik pada support anorganik, seperti silica ${ }^{[1-3]}$ maupun pada support organik, seperti poly-4-vinylpyridine (P4VP). ${ }^{[4]}$ Pada banyak kasus, proses grafting katalis homogen pada material support terjadi melalui ikatan kovalen. Metoda ikatan kovalen ini dilaporkan dapat memberikan pengaruh pada kereaktifan dan keselektifan dari katalis karena berakibat mengurangi asiditas Lewis ion logam pusatnya. ${ }^{[9-12]}$

Pada penelitian ini dilakukan penggraftingan suatu garam tembaga(II) nitrat dalam pelarut asetonitril pada permukaan silika yang dimodifikasi. Komplek $\left[\mathrm{Cu}\left(\mathrm{NCCH}_{3}\right)_{6}\right]^{2+}$ yang terbentuk dan proses graftingnya pada permukaan silika induk tidak dapat terjadi secara kovalen maupun ionik, maka permukaan silika terlebih dahulu dimodifikasi dengan anilin $\left(\mathrm{C}_{6} \mathrm{H}_{5} \mathrm{NH}_{2}\right)$ sebagai basa BrØnsted dan selanjutnya direaksikan dengan aluminium triklorida $\left(\mathrm{AlCl}_{3}\right)$ yang bertindak sebagai asam Lewis sehingga terbentuk 
permukaan silika bermuatan negatif. Spesies $\left[\mathrm{Cu}\left(\mathrm{NCCH}_{3}\right)_{6}\right]^{2+}$ yang berhasil digrafting pada silika modifikasi selanjutnya dikarakterisasi dengan FTIR dan EDX.

\section{METODOLOGI PENELITIAN}

\section{Prosedur Sintesis}

Peralatan yang digunakan diantaranya adalah beberapa peralatan gelas, magnetic stirer, timbangan, oven, furnace, corong Büchner dan desikator. Sedangkan instrument yang digunakan adalah mikroskop optik, FTIR, dan SEM-EDX. Bahan-bahan kimia yang digunakan adalah silika gel 60 mesh $\left(\mathrm{SiO}_{2}\right)$, anilin $\left(\mathrm{C}_{6} \mathrm{H}_{5} \mathrm{NH}_{2}\right)$, aluminium triklorida heksahidrat $\left(\mathrm{AlCl}_{3} .6 \mathrm{H}_{2} \mathrm{O}\right)$, tembaga(II) nitrat pentahidrat $\left(\mathrm{Cu}\left(\mathrm{NO}_{3}\right)_{2} .5 \mathrm{H}_{2} \mathrm{O}\right)$, asetonitril $\left(\mathrm{CH}_{3} \mathrm{CN}\right)$, toluen $\left(\mathrm{C}_{6} \mathrm{H}_{5} \mathrm{CH}_{3}\right)$ yang keseluruhan bahan tersebut diperoleh dari Merck dengan kualitas pro analysis (p.a) serta aquades. Pengukuran sampel dengan FTIR dilakukan di Fakultas Farmasi Unand Padang sedangkan pengukuran EDX dilakukan di Badan Survey Geologi Nasional, Bandung.

Sebelum dilakukan proses grafting, jumlah dari gugus silanol harus diketahui terlebih dahulu. Hal ini menjadi sangat penting untuk menaksir kapasitas adsorpsi dan jumlah maksimum katalis yang dapat digrafting pada surface silanol (silanol permukaan). ${ }^{[9]}$ Penentuan jumlah gugus silanol permukaan dapat ditentukan secara teoritis berdasarkan nilai luas permukaan dan pengaruh temperatur pemanasan silika yang sedang diuji terhadap kandungan jumlah gugus $>\mathrm{Si}-\mathrm{OH}$ per $\mathrm{nm}^{2}{ }^{\left[{ }^{[13]}\right.}$ Selanjutnya, untuk reaksi modifikasi dan grafting ion komplek $\left[\mathrm{Cu}\left(\mathrm{NCCH}_{3}\right)_{6}\right]^{2+}$ maka nilai perbandingan mol didasarkan pada rasio molar $>\mathrm{Si}-\mathrm{OH}: \mathrm{N}$ (anilin), $>\mathrm{Si}-\mathrm{OH}: \mathrm{Al}$ $\left(\mathrm{AlCl}_{3}\right)$ dan $>\mathrm{Si}-\mathrm{OH} \mathrm{Cu}$ adalah $1: 1,2 .^{[1]}$

Silika gel yang telah ditentukan jumlah gugus silanolnya dipanaskan pada suhu $200^{\circ} \mathrm{C}$ selama 1 jam. Prosedur ini bertujuan untuk membuka pori dan mengaktifasi permukaan silika. Kemudian bahan tersebut dicampurkan dengan $7 \mathrm{~mL}$ anilin dalam $50 \mathrm{~mL}$ toluen. Suspensi ini distirer pada temperatur ruang selama 24 jam dan setelah itu disaring dengan corong Buchner dengan bantuan pompa vakum.
Padatan yang diperoleh dikeringkan dalam desikator dan dikarakterisasi dengan FTIR. Bahan yang diperoleh diberi label Si-An.

Padatan Si-An dicampurkan dengan $10 \mathrm{~g} \mathrm{AlCl}_{3}$ anhidrat dalam $50 \mathrm{~mL}$ toluen. Campuran distirer selama 24 jam pada temperatur ruang dan suspensi biru muda (silika- $\mathrm{AlCl}_{3}$ ) yang terbentuk kemudian disaring dengan corong Buchner dengan bantuan pompa vakum, dicuci dengan toluen sebanyak empat kali. Padatan yang diperoleh dikeringkan dan dikarakterisasi dengan FTIR. Material silika terfungsionalisasi ini diberi nama Si-Al dan disimpan dalam desikator hingga digunakan untuk prosedur kerja selanjutnya.

Sebanyak 3,5 $\mathrm{g} \mathrm{Cu}\left(\mathrm{NO}_{3}\right)_{2}$ anhidrat direaksikan dengan $50 \mathrm{~mL}$ asetonitril. Setelah distirer selama 30 menit kemudian ditambahkan $10 \mathrm{~g}$ Si-Al. Suspensi distirer lagi selama 24 jam pada temperatur ruang. Katalis yang terbentuk dicuci dengan asetonitril sebanyak empat kali, dikeringkan dan disimpan di dalam vakum hingga dilakukan karakterisasi. Pada penelitian ini, katalis tergrafting tersebut diberi nama amobilat Si-Al-CuN.

\section{Karakterisasi Katalis Tergrafting}

Pelacakan gugus-gugus fungsi yang terdapat pada Si-Al-CuN (C-N anilin, N-H anilin, CN asetonitril, Si-O-Si silika dan $\mathrm{Si}-\mathrm{O}-\mathrm{H}$ silika) dilakukan dengan pengukuran menggunakan FTIR. Sementara itu komposisi unsur-unsur penyusun Si-Al-CuN ditentukan dengan EDX.

\section{HASIL DAN PEMBAHASAN}

\section{Penentuan Jumlah Gugus Silanol ( $\alpha$ он) Silika Permukaan}

Penentuan jumlah gugus $>\mathrm{Si}-\mathrm{OH}$ (silanol) permukaan yang dilambangkan dengan $\alpha \mathrm{OH}$ dari silika induk bertujuan untuk menentukan kapasitas adsorpsi dan jumlah maksimum katalis tembaga(II) asetonitril yang dapat digrafting. ${ }^{[9]} \alpha$ OH dari silika induk dapat ditentukan secara teoritis berdasarkan pada pengaruh temperatur pemanasan silika. ${ }^{[13]}$

Pada penelitian ini, pemanasan silika induk dilakukan pada temperatur $200{ }^{\circ} \mathrm{C}$, sehingga 
$\alpha_{\text {OH }}$ yang sesuai adalah $4,60 \mathrm{~nm}^{-2}$. Setelah nilai $\alpha_{\mathrm{OH}}$ diperoleh dan luas permukaan silika juga diketahui dari jenis dan ukuran partikel silika, ${ }^{[13]}$ maka jumlah mol $>\mathrm{Si}-\mathrm{OH}$ untuk sejumlah silika (gram) yang digunakan sebagai support dapat ditentukan melalui persamaan:

$$
\begin{gathered}
\begin{array}{l}
\text { Jumlah mol silanol }=\left[\mathrm{A}\left(\mathrm{SiO}_{2}\right) \times \alpha\right. \text { OH } \\
\left.\mathrm{m}\left(\mathrm{SiO}_{2}\right)\right] / \mathrm{N}_{\mathrm{A}}
\end{array} \\
\begin{array}{r}
=\left[420 \mathrm{~m}^{2} \mathrm{~g}^{-1} \times 4,6 \times 10^{18}\right. \\
\left.\mathrm{m}^{-2} \times 20 \mathrm{~g}\right] / 6,02 \times 10^{23} \mathrm{~mol}^{-1} \\
=0,064 \mathrm{~mol}^{6}
\end{array}
\end{gathered}
$$

Dalam pengerjaan selanjutnya, mol silanol yang diperoleh menjadi dasar untuk menentukan jumlah anilin, aluminium klorida dan tembaga(II) nitrat dengan semua perbandingan mol dibuat sesuai dengan penelitian sebelumnya ${ }^{[9]}$ dimana $>$ Si-OH:N $=1$ : 1,2, $>$ Si-OH:Al = $1: 1,2$ dan $>$ Si-OH:Cu $=1$ : 1,2 .

\section{Karakterisasi}

\section{Hasil Analisis dengan Fourier Transform Infar Red (FTIR)}

Analisis FTIR dilakukan untuk senyawa komplek tembaga(II) asetonitril, silika induk, silika modifikasi ( $\mathrm{Si}-\mathrm{Al}$ ) dan senyawa komplek tembaga(II) asetonitril yang telah digrafting pada permukaan silika modifikasi (Si-Al-CuN) seperti yang ditunjukkan pada Gambar 1.

Pada Gambar 1.a. munculnya dua puncak tajam dengan intensitas lemah pada daerah sekitar 2300-2400 $\mathrm{cm}^{-1}$ yang diasumsikan sebagai vibrasi ulur $\mathrm{CN}$ dari $\mathrm{CH}_{3} \mathrm{CN}$ terikat yang telah mengalami pergeseran dari 2250$2290 \mathrm{~cm}^{-1}$ (vibrasi $\mathrm{CH}_{3} \mathrm{CN}$ bebas). Keberadaan dua puncak diduga karena terbentuknya ion komplek $\left[\mathrm{Cu}\left(\mathrm{NCCH}_{3}\right)_{6}\right]\left(\mathrm{NO}_{3}\right)_{2}$ (persamaan 1) sebab apabila hanya muncul satu puncak maka kompleknya adalah $\left[\mathrm{Cu}\left(\mathrm{NCCH}_{3}\right)_{4}\right]\left(\mathrm{NO}_{3}\right)_{2}{ }^{[10]}$ Vibrasi ulur simetris $\mathrm{O}-\mathrm{N}-\mathrm{O}$ dari anion nitrat ditunjukkan oleh puncak tajam pada daerah sekitar $1300-1400 \mathrm{~cm}^{-1} \cdot{ }^{[15]}$

$$
\begin{array}{ll}
\mathrm{Cu}\left(\mathrm{NO}_{3}\right)_{2}+ & +6 \mathrm{CH}_{3} \mathrm{CN} \\
{\left[\mathrm{Cu}\left(\mathrm{NCCH}_{3}\right)_{6}\right]\left(\mathrm{NO}_{3}\right)_{2}} & \text { (Persamaan 1) }
\end{array}
$$

Puncak-puncak serapan yang karakteristik untuk silika (Gambar 1.b) terdapat pada daerah antara $1300-700 \mathrm{~cm}^{-1}\left(1120-1000 \mathrm{~cm}^{-1}\right.$ puncak lebar dan 700-850 $\mathrm{cm}^{-1}$ puncak tajam). Puncakpuncak pada daerah tersebut, masingmasingnya berkaitan dengan vibrasi ulur $\mathrm{Si}-$ $\mathrm{O}-\mathrm{Si}$ dan vibrasi tekuk dari $\mathrm{Si}-\mathrm{OH}$ (gugus silanol).

Setelah dimodifikasi (Gambar 1.c), intensitas puncak serapan pada daerah 700-850 $\mathrm{cm}^{-1}$ menurun drastis yang mungkin disebabkan telah terjadinya reaksi antara gugus silanol dengan $\mathrm{AlCl}_{3}$. Kombinasi vibrasi ulur $\mathrm{Si}-\mathrm{O}$ Si dengan $\mathrm{Si}-\mathrm{O}-\mathrm{Al}$ antara $1400-1450 \mathrm{~cm}^{-1}$ tidak muncul sama sekali. Adanya puncak serapan yang sangat tajam pada daerah antara $1400-1500 \mathrm{~cm}^{-1}$ diprediksi sebagai vibrasi ulur $\mathrm{C}-\mathrm{N}$ aromatis (dari anilin) yang tergeser dari daerah 1250-1400 $\mathrm{cm}^{-1}$. Sedangkan sebuah puncak tajam lagi pada daerah $750-850 \mathrm{~cm}^{-1}$ dapat pula menjadi indikasi keberadaan $\mathrm{H}-$ $\mathrm{N}-\mathrm{H}$ wagging dari $\mathrm{C}_{6} \mathrm{H}_{5} \mathrm{NH}_{3}{ }^{+}$. Pada daerah 2400-2800 $\mathrm{cm}^{-1}$ jelas terlihat munculnya puncak serapan yang kemungkinan besar merupakan vibrasi $\mathrm{C}-\mathrm{H}$ aromatik dari anilin. ${ }^{(2}$ dan 13) Semua data yang telah dikemukakan tersebut memberikan konfirmasi yang cukup signifikan mengenai keberadaan silika modifikasi (Si-Al). 


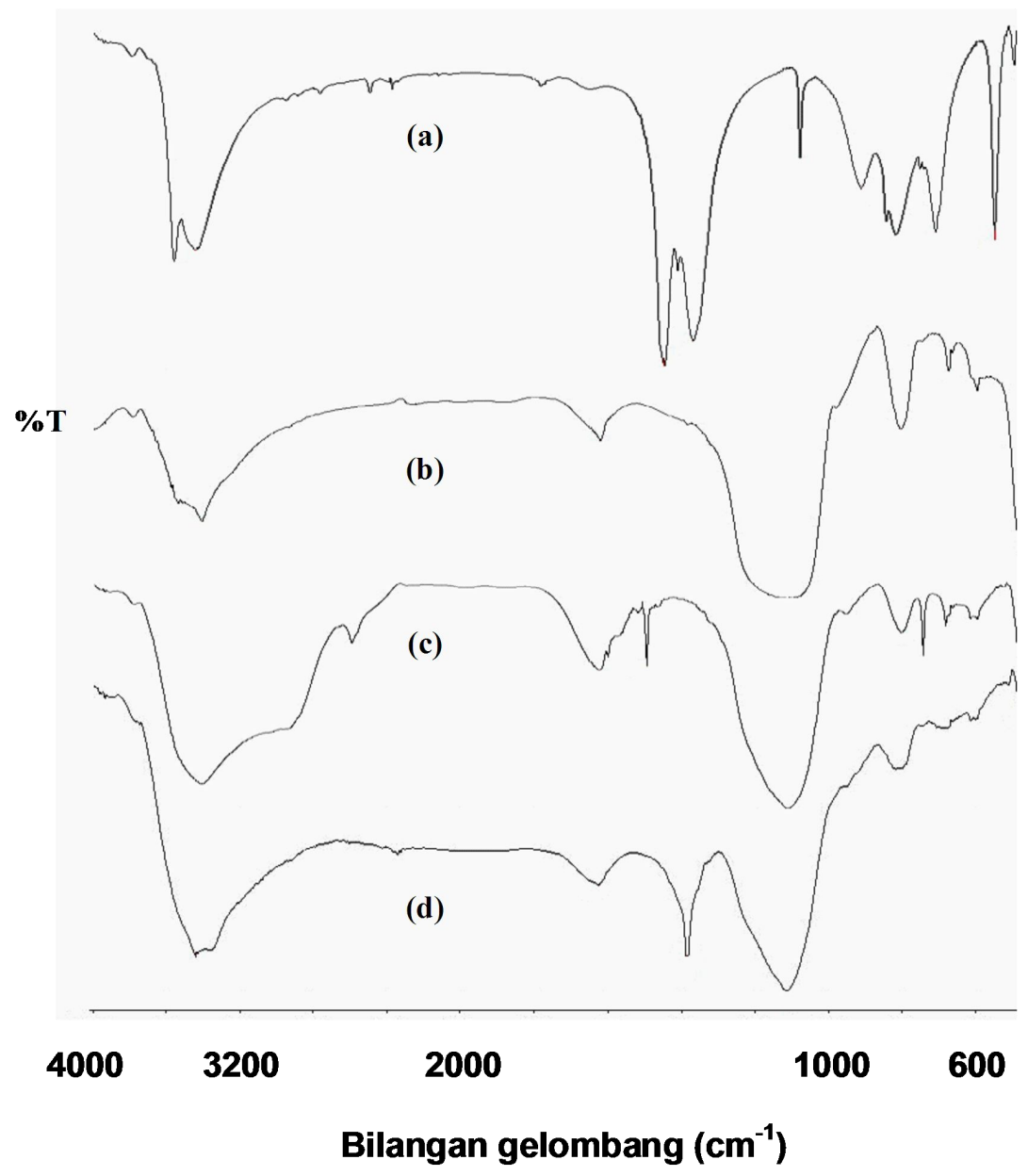

Gambar 1. Spektra FTIR komplek $\mathrm{Cu}(\mathrm{II})$ asetonitril (a), silika induk (b), silika-AlCl 3 (c) dan amobilat (d).

Grafting ion komplek $\left[\mathrm{Cu}\left(\mathrm{NCCH}_{3}\right)_{6}\right]^{2+}$ pada permukaan silika modifikasi diperlihatkan dengan munculnya puncak serapan halus pada daerah sekitar 2450-2380 $\mathrm{cm}^{-1}$ dan satu puncak serapan tajam pada daerah sekitar $1380 \mathrm{~cm}^{-1}$ yang mungkin berasal dari tembaga nitrat yang terserap secara fisika (Gambar 4.d). Vibrasi gugus nitril $(\mathrm{CN})$ dari asetonitril bebas akan ditemukan pada daerah sekitar 2253 dan 2293 $\mathrm{cm}^{-1}$. Dikarenakan adanya koordinasi asetonitril sebagai ligan pada ion pusat $\mathrm{Cu}(\mathrm{II})$, maka kedua puncak serapan ini juga bergeser ke daerah sekitar 2300-2400 $\mathrm{cm}^{-1}$.

Hilangnya puncak-puncak serapan silika terfungsionalisasi yang berasal dari ion $\left(\mathrm{C}_{6} \mathrm{H}_{5} \mathrm{NH}_{3}\right)^{+}$pada daerah sekitar 1400 sampai dengan $1250 \mathrm{~cm}^{-1}$ menunjukkan bahwa pertukaran ion mungkin terjadi menurut persamaan 2 .

$2\left[\left(>\mathrm{Si}-\mathrm{O} \rightarrow \mathrm{AlCl}_{3}\right)^{-}\left(\mathrm{C}_{6} \mathrm{H}_{5} \mathrm{NH}_{3}\right)^{+}\right]+$

$\left[\mathrm{Cu}\left(\mathrm{NCCH}_{3}\right)_{6}\right]^{2+}\left(\mathrm{NO}_{3}\right)_{2}{ }^{-} \rightarrow$

$\left(>\mathrm{Si}-\mathrm{O} \rightarrow \mathrm{AlCl}_{3}\right)_{2}-\left[\mathrm{Cu}\left(\mathrm{NCCH}_{3}\right)_{6}\right]^{2+}+$

$2\left[\left(\mathrm{C}_{6} \mathrm{H}_{5} \mathrm{NH}_{3}\right)^{+}\left(\mathrm{NO}_{3}\right)_{2}{ }^{-}\right] \quad$ (Persamaan 2)

\section{Hasil analisis Energy Dispersive X-ray (EDX)}

Analisis EDX berguna untuk menyelidiki komposisi unsur-unsur penyusun dari sampel. Pada penelitian ini, sampel yang diselidiki komposisi unsur-unsur penyusunnya adalah silika induk $\left(\mathrm{SiO}_{2}\right)$ dan amobilat $([>\mathrm{Si}-\mathrm{O} \rightarrow$ $\left.\left.\mathrm{AlCl}_{3}\right]_{2}\left[\mathrm{Cu}\left(\mathrm{NCCH}_{3}\right)_{6}\right]\right)$. 

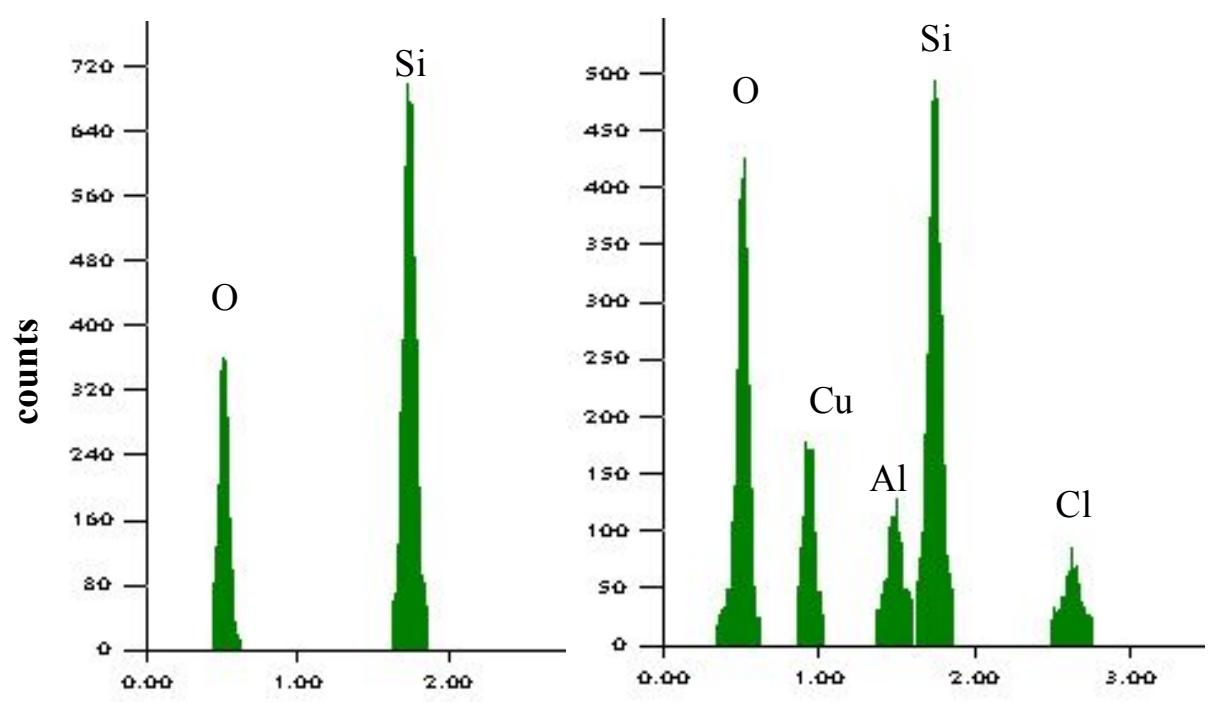

keV

Gambar 2. Pola spektrum EDX dari silika induk (kiri) dan amobilat (kanan)

Hasil pengukuran (Gambar 2) menunjukkan bahwa material induk yang digunakan adalah silika dengan rumus molekul $\mathrm{SiO}_{2}$ dimana presentase masing-masing unsurnya sesuai dengan perbandingan mol 1:2 (Tabel 1). Dari Tabel 1 juga dapat dilihat bahwa semua unsur utama penyusun dari amobilat teridentifikasi secara signifikan. Berdasarkan perhitungan teoritis, seharusnya kandungan ion logam pusat $\mathrm{Cu}$ adalah 12,48 \% namun karena tidak semuanya yang tergrafting pada support maka nilai yang diperoleh dari hasil analisis EDX adalah 6,69\%. Hal ini menandakan bahwa tidak seluruhnya ion tembaga(II) dapat tergrafting pada permukaan silika modifikasi sebagai ion komplek heksaasetonitril tembaga(II), sebagiannya diperkirakan hanya teradsorpsi secara fisika sebagai tembaga(II) nitrat sebagaimana yang telah dikonfirmasi oleh spektra FTIR pada Gambar 1.d.

Tabel 1. Komposisi penyusun silika induk dan amobilat dan kandungan logam (metal loading) hasil analisa EDX

\begin{tabular}{ccc}
\hline \multirow{2}{*}{ Unsur } & \multicolumn{2}{c}{ Kandungan $(\%)$} \\
\cline { 2 - 3 } & Silika induk & Amobilat \\
\hline $\mathrm{Si}$ & 46,74 & 28,85 \\
$\mathrm{O}$ & 53,26 & 37,67 \\
$\mathrm{Al}$ & - & 5,31 \\
$\mathrm{Cl}$ & - & 6,30 \\
$\mathrm{Cu}$ & - & 6,69 \\
\end{tabular}

\section{KESIMPULAN}

Sintesis silika modifikasi dan katalis tergrafting telah berhasil dilakukan. Hal ini dibuktikan melalui analisis EDX yang mengkonfirmasikan adanya $\mathrm{Si}, \mathrm{O}, \mathrm{Al}, \mathrm{Cl}$ dan $\mathrm{Cu}$ yang merupakan unsur-unsur penyusun amobilat. Sedangkan kandungan logam $\mathrm{Cu}$ pada amobilat adalah sebesar $50 \%$ dari perhitungan teoritis yang sebagian lainnya diperkirakan hanya teradsorpsi secara fisika. Keberhasilan proses modifikasi silika induk serta grafting ion komplek tembaga(II) dibuktikan melalui analisis FTIR dengan 
adanya puncak-puncak serapan gugus fungsi dari $\mathrm{C}_{6} \mathrm{H}_{5} \mathrm{NH}_{2}, \mathrm{AlCl}_{3}, \mathrm{CH}_{3} \mathrm{CN}$ dan $\mathrm{Cu}\left(\mathrm{NO}_{3}\right)_{2}$. Terbentuknya spesies anionik $\left(>\mathrm{Si}-\mathrm{OAlCl}_{3}\right)^{-}$ pada permukaan silika modifikasi ternyata memberikan pengaruh terhadap morfologi amobilat. Hal ini dikonfirmasikan oleh hasil analisis SEM dan mikroskop optik yang memperlihatkan bentuk, ukuran dan dispersi partikel amobilat menjadi lebih homogen dibandingkan dengan silika induk.

\section{Ucapan terima kasih}

Kami mengucapkan terima kasih pertama-tama kepada Lembaga Penelitian Universitas Andalas atas Hibah Bersaing TA 2009 yang telah dipercayakan kepada kami. Selanjutnya kepada mahasiswa kami, saudara Hosli Hidayat, yang telah menyelesaikan penelitian ini dengan baik. Ucapan terima kasih juga buat pimpinan dan analis Laboratorium Kimia Material dan Pengukuran Jurusan Kimia Unand.

\section{DAFTAR PUSTAKA}

1. X. S. Zhao, X. Ying Bao, Wanping Guo, and Fang Yin Lee, Amobilizing Catalysts on Porous Materials, Materials Today, Vol. 9, No. 3, p. 32 (2006).

2. H. U. Blaser, A. Indolese, and A. Schnyder, Applied Homogeneous Catalysis by Organometallic Complexes, Current Science, Vol. 78, No. 11, p. 1336 (2000).

3. C. E. Housecroft, , A. G. Sharpe, Inorganic Chemistry, $2^{\text {nd }} e d$., Pearson Prentice Hall (2005)

4. Syukri, A. K. Hijazi, A. Sakthivel, A. I. Al-Hmaideen and F. E. Kühn, Heterogenization of Solvent-Ligated Copper(II) Complexes on Poly(4Vinylpyridine) for the Catalytic Cyclopropanation of Olefins, Inorganica Chimica Acta, 360, p. 197 (2007)

5. C. Sumate, S. Chavadej, E. Gulari, Borane-Functionalized Silica Supports In Situ Activate Heterogenoeus Zirconocene Catalysts for MAO-Free Ethylene Polymerization, Journal of Molecular Catalysis, 185, p. 167 (2002)

6. P.K. Jal, S. Patel, B.K. Mishra, Chemical Modification of Silica Surface by Amobilization of Functional Groups for
Extractive Concentration of Metal Ions, Talanta, 62, p. 1005 (2004).

7. M. P. Price, James H. Clark and Duncan J. Macquarrie, Modified Silicas for Clean Technology, J. Chem. Soc., Dalton Trans., p. $101(2000)$

8. X. S. Zhao, X. Ying Bao, Wanping Guo, and Fang Yin Lee, Amobilizing Catalysts on Porous Materials, Materials Today, Vol. 9, No. 3, p. 32 (2006)

9. Syukri, C. E. Fischer, A. I. Al-Hmaideen, Yang Li, Ying Zheng, F. E. Kühn, Modified MCM-41-Supported Acetonitrile Ligated Copper(II) and its Catalytic Activity in Cyclopropanation of Olefins, Microporous and Mesoporous Materials, 113, p. 171 (2008).

10. A. Sakthivel. S. Syukri, A. K. Hijazi and F. E. Kühn, Heterogenization of $\left[\mathrm{Cu}\left(\mathrm{NCCH}_{3}\right)_{6}\right]\left[\mathrm{BF}_{4}\right]_{2}$ on mesoporous AlMCM-41/AlMCM-48 and its Application as Cycloproponation Catalyst, Catalysis Letters, 111, p. 43 (2006)

11. A. Sakthivel. A. K. Hijazi, M. Hanzlik, A. S.T. Chiang, F. E. Kühn, 2005, Heterogenization of $\left.\mathrm{Cu}\left(\mathrm{NCCH}_{3}\right)_{6}\right]\left[\mathrm{B}\left(\mathrm{C}_{6} \mathrm{~F}_{5}\right)_{4}\right]_{2}$ and its Application in Catalytic Olefin Aziridination, Applied Catalysis A: General, 294, p. 161

12. Syukri, A. K. Hijazi, A. Sakthivel, A. I. Al-Hmaideen and F. E. Kühn, Heterogenization of Solvent-Ligated Copper(II) Complexes on Poly(4Vinylpyridine) for the Catalytic Cyclopropanation of Olefins, Inorganica Chimica Acta, 360, p. 197 (2007)

13. Bergna, Horacio E., William O. Roberts, Colloidal Silica: Fundamentals and Applications, Surfactant Science Series, Vol. 131, CRC Press (2006)

14. Herguth, William R., Applications of Scanning Electron Microscopy and Energy Dispersive Spectroscopy (SEM/EDS) to Practical Tribology Problems, Herguth Laboratories, Inc

15. Barbara Stuart, Infrared Spectroscopy: Fundamentals and Applications, John Wiley \& Sons, Ltd (2004). 